\title{
The discovery of the stethoscope by T. R. H. Laënnec (1781-1826)
}

\author{
B. Lüderitz
}

Received: 3 April 2009 / Accepted: 6 April 2009 /Published online: 29 July 2009

(C) Springer Science + Business Media, LLC 2009

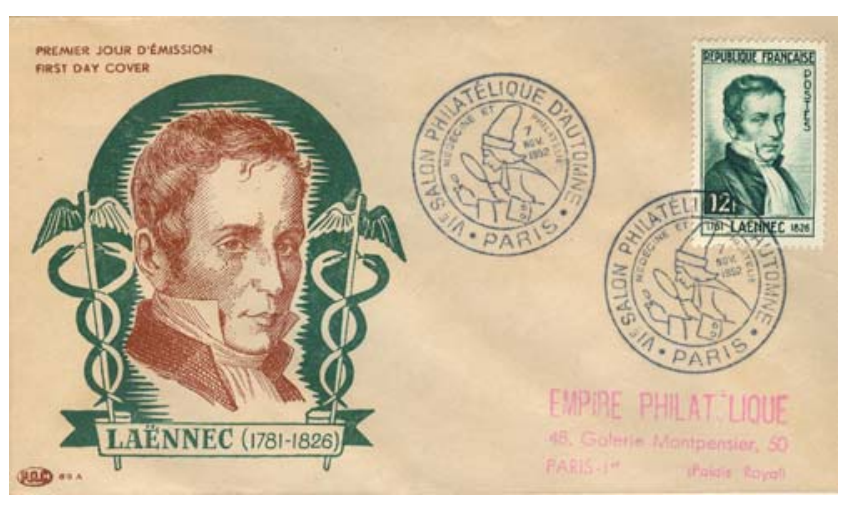

One hundred ninety years ago (in 1819), an epochal work was published, which was to change the art of healing radically. DE L'AUSCULTATION MÉDIATE OU TRAITÉ DU DIAGNOSTIC DES MALADIES DES POUMONS ET DU COEUR (On Mediate Auscultation or Treatise on the Diagnosis of the Diseases of the Lungs and Heart) 928 pages in two volumes, already celebrated as the "New Testament of Medicine" at that time. In 1823, the author was admitted to the Mount Olympus of French science, the "Collège de France", as professor of the medical faculty of Paris and head of the Charite (succeeding Corvisart) and as chevalier of the Legion of Honor--By inventing the stethoscope, Théophile René Hyacinthe Laënnec (as is his full name) had steered medicine towards carefully targeted analysis and precise diagnostics as opposed to the previously dominating form of medicine, which was based on guesswork and obscure theorems. Naturally, this also affected the strange methods of treatment derived from these dogmas, with their enemas, leeches, bloodletting, etc.

\section{B. Lüderitz $(\bowtie)$}

Department of Medicine and Cardiology, University of Bonn,

Sigmund-Freud-Str. 25,

Bonn D-53105, Germany

e-mail: b.luederitz@uni-bonn.de
With his discovery, Laënnec had accomplished something fundamental and enduring in his short but eventful life.

The son of an advocate was born on 17 February 1781 in Quimper (Brittany), today the capital of the department of Finistère (Fig. 1). After the early death of his motherpresumably from pulmonary tuberculosis-, he leaves Quimper and grows up at an uncle's home. During the revolutionary wars, Laënnec witnesses the besiegement of Nantes and the care for the wounded. Fascinated by medicine at an early age, he starts his formal medical education at the age of 19 at the Ecole de Médicine in Paris. Important personages, such as Dupuytren and Corvisart, Napoleon's personal physician, are among his teachers, and the latter instructs him in the almost forgotten art of percussion, which had already been described in 1761 by the Austrian physician Leopold Auenbrugger-—Laënnec's fondness for music, especially for playing the flute, which he pursued with passion-including the occasional public performance at aristocrats' homes - is not without relevance in regard to his later discovery and interpretation of the auscultation results. His musical talent would have decisively enhanced his impressive ability to detect and evaluate (medical) sounds and noises.

From the very beginning, i.e. already in ancient and medieval times, physicians had attempted auscultation (lat. auscultare $=$ to listen), chiefly by placing the ear directly on the chest or back of the patient. Laënnec also performed his medical examinations in this manner at the Hôpital Necker in Paris. The actual invention of the stethoscope by Laënnec can be traced back to several inspirations. In December 1816, Laënnec observed two children in the park of the Louvre, who put their ears at the ends of a wooden bar and transmitted tapping signals to each other, which were acoustically amplified by the wood. According to Laënnec's own words, the clinical application of this observation emerged when he was consulted by a young woman who showed symptoms of a general cardiac disease. The age and 


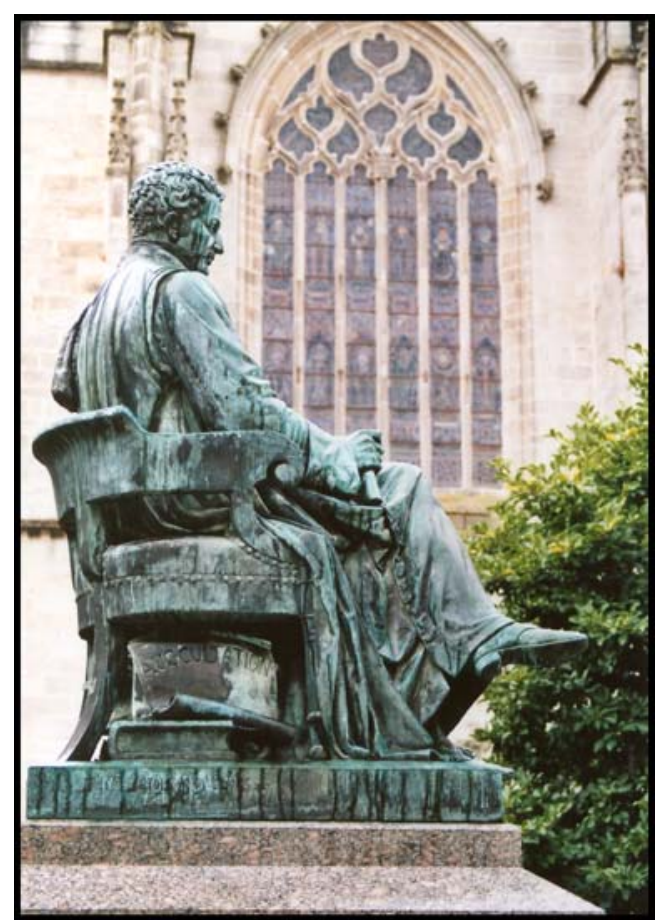

Fig. 1 Laënnec statue (by E. L. Lequesne) on the Place de la Cathedrale in Quimper (Brittany), his place of birth (17 February 1781). The inventor of the stethoscope in the robes of a professor. In his hand the famous stethoscope, at the side of the armchair "Le traité d'auscultation médiate" from 1819

gender of the patient prohibited him from placing his ear directly on her chest. Instead, he took a paper notebook, made it into a tight roll, placed the one end on the heart region, and, putting his ear on the other end, he was as surprised as he was satisfied to hear the sequence of heartbeats much clearer and cleaner than it had ever been possible by a direct placement of the ear. The idea of the stethoscope was born!-Laënnec constructed a more solid version of the ear trumpet in the form of a wooden hollow cylinder of $25 \mathrm{~cm}$ length and $2.5 \mathrm{~cm}$ diameter, which, in a later variant, could be assembled from three parts (Figs. 2, 3). Laënnec used cedar or ebony wood and manufactured the stethoscope himself. On a wood lathe, he turned out a total of 3,500 exemplars in 3 different models. He sold the stethoscopes at a low price together with his book, published in the first edition in 1819-a visionary anticipation of a marketing idea that can only be called shrewd in colloquial terms. The term stethoscope, by the way, is made up of the two Greek words stethos = chest and skopein $=$ to see, observe. Other names, such as "pectoriloquist", "sonometer", or "thoraciloquist" were scrapped. With the help of the new instrument, the examining physician was able to hear various breathing sounds, such as bronchial breathing, shoulder sounds, as well as heart tones, diastolic sounds, and the galloping rhythm characteristic for mitral stenosis. Laënnec, together with Harvey and Senac, was thus among the first to describe atrial fibrillation, after he had noticed the variation of the heart contraction, with or without palpable pulse - in accordance with the modern definition of pulse deficit.

Laënnec's interpretation of the heart sounds S1 and S2 was not correct according to our current state of knowledge. He ascribed $\mathrm{S} 1$ to the ventricular systole and $\mathrm{S} 2$ to the atrial systole, whereas today we differentiate the atrioventricular valveclosing sound and the ventricular outflow sound of the valve.

Of interest are the musical analogies that Laënnec chose to describe the various acoustic phenomena. For instances, echoes of the sound reproduction of contrabass, cello, and harp are mentioned.

Laënnec's discovery soon found worldwide use and recognition. Nevertheless, his scientific and pathophysiological ideas, based on the mediate, i.e. indirect, auscultation - as Laënnec called his examination technique - did not remain uncontested - especially in the French capital, Paris. François Broussais in particular, a well-known physician also hailing from Brittany, attacked Laënnec sharply to the point of personal denigration and public defamation, which was then returned in kind by Laënnec. Interestingly enough, great French hospitals today carry the name of both rivals of old. Despite all animosities, Laënnec gained increasingly in prestige and esteem. He auscultated the chest of Madame de Staël as well as that of Chateaubriand and various cardinals.

Laënnec was a Breton with heart and soul, he loved the country and its people; he spoke their (Breton) language as well as Latin and Greek and the world languages Italian, English, and German; French, of course, anyway. He had a close relationship with the church and joined the influential (Catholic) congregation of the Virgin Mary in 1803. Since 1824-thus 2 years before his death-Laënnec was married to one of his cousins.-Laënnec was again and again drawn back to his native region, where he enjoyed the fresh air on extended hikes, which later also helped to alleviate his tuberculosis-caused symptoms. Brittany, i.e. his house Kerlouarnec, was also the place to which Laënnec withdrew when he felt that the end of his life was near. On 09 June 1826 , he believed to have only 1 week

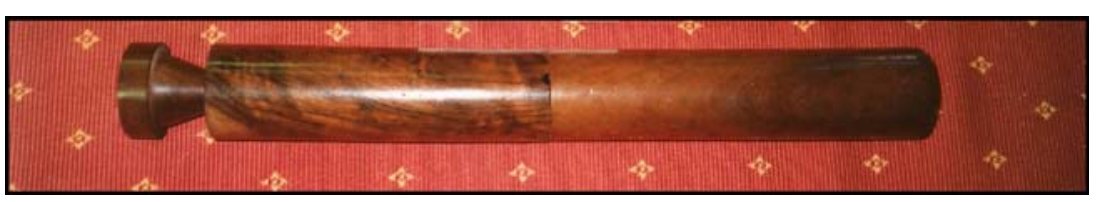

Fig. 2 The first wooden stethoscope built by Laënnec himself from boltable component parts (from the Musée Laënnec in the Faculté des Lettres of the University of Nantes, France) 
Fig. 3 Model of Laënnec's stethoscope from the 2 nd edition of his famous book "De L'Auscultation Médiate", published in the year of his death. 1: (from left to right) Cylinder, 2: Longitudinal section through the stethoscope, 3: Longitudinal section without chestpiece, 4 : Chestpiece, 5: Lower part of the stethoscope, 6: Diameter of the stethoscope

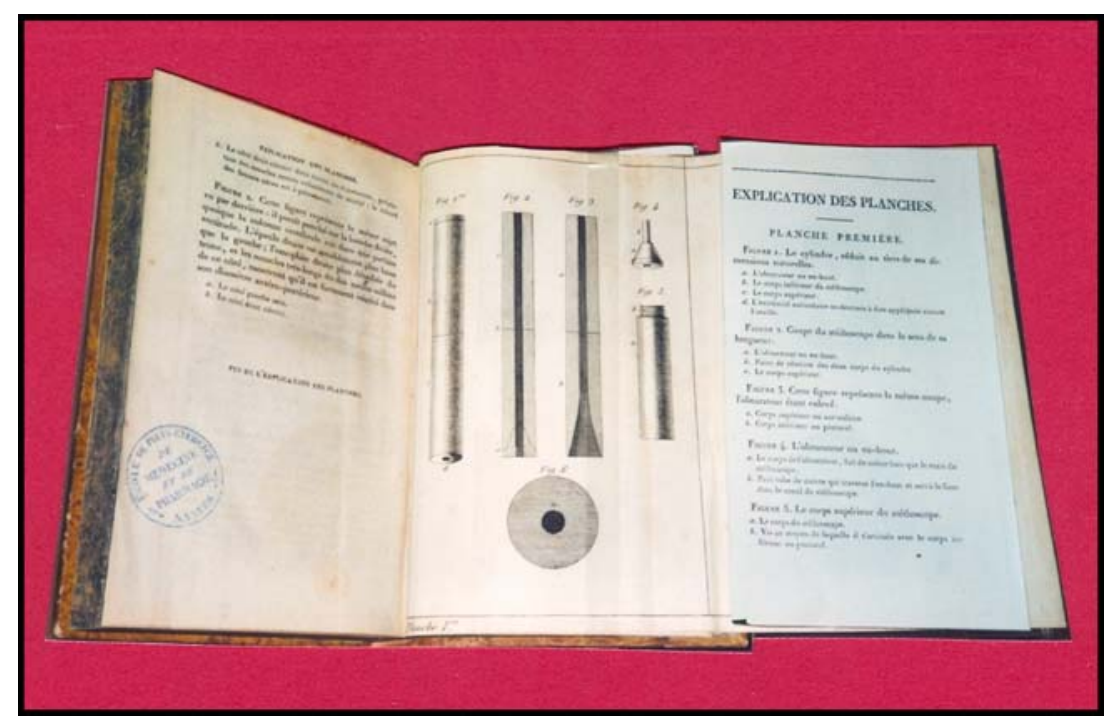

left to live. In reality, he died on 13 August 1826, from pulmonary tuberculosis, the disease, to the diagnosis of which he had contributed so tremendously. His grave can be found in the cemetery of Ploaré near Donarnenez, not far from his estate "Manoir Laënnec in Kerlouarnec", which is located close to Quimper, his place of birth. Laënnec died highly venerated; memorial

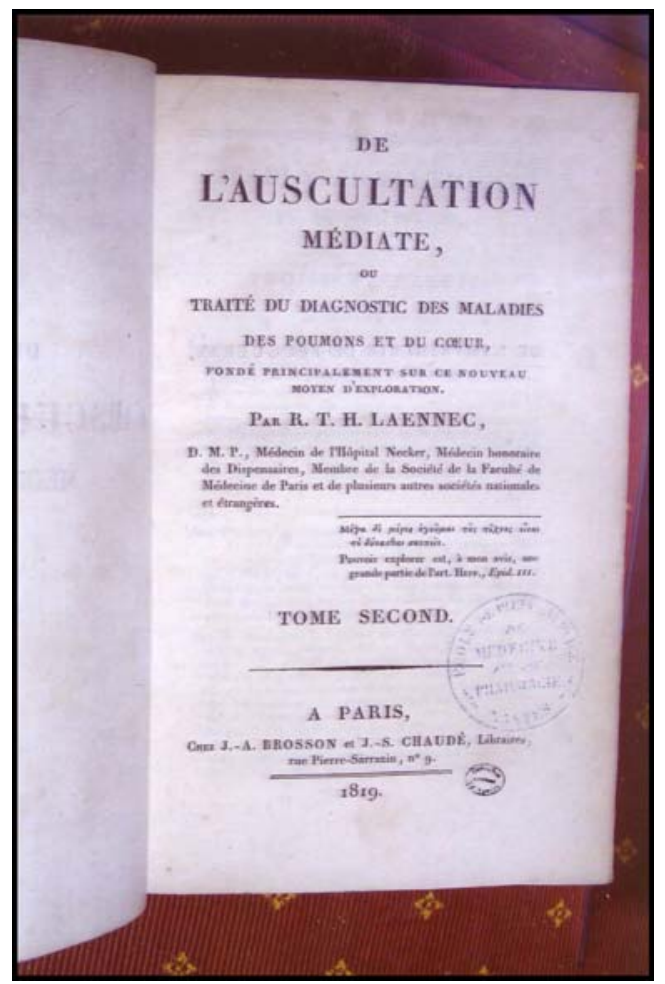

Fig. 4 The second volume of Laënnec's main opus on the mediate (indirect) auscultation from 1819 (2nd edition 1826), which was offered for sale together with the stethoscope he had invented, developed, and manufactured plaques on his former house of birth and on his last residence bear witness to this, as do statues in Quimper on the cathedral square and in the Centre Hôspitalier in Quimper. Several hospitals carry his name, among them the new clinic in Quimper; the old hospital, which used to be named for Laënnec, is now a retirement home and also named for the great son of the Breton capital. His invention of the stethoscope is worldwide regarded an indispensable accessory for every physician and quite simply as the symbol of a physician's work (Figs. 4, 5, 6, 7).

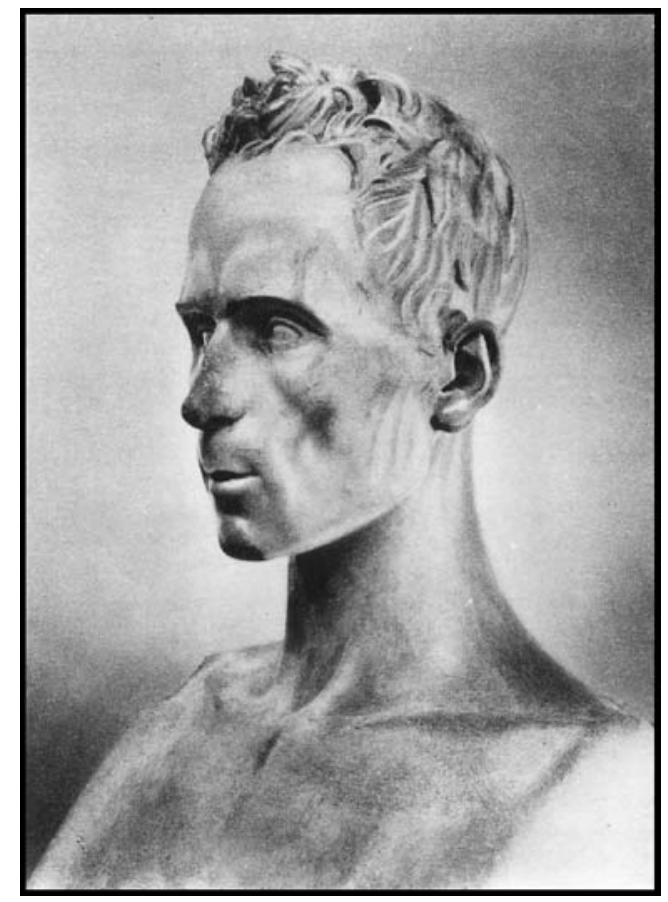

Fig. 5 René Théophile Laënnec's bust by E. F. Lequesne, the creator of the Laënnec statue in Quimper (Medical and Pharmaceutical Faculty of the University of Nantes) 


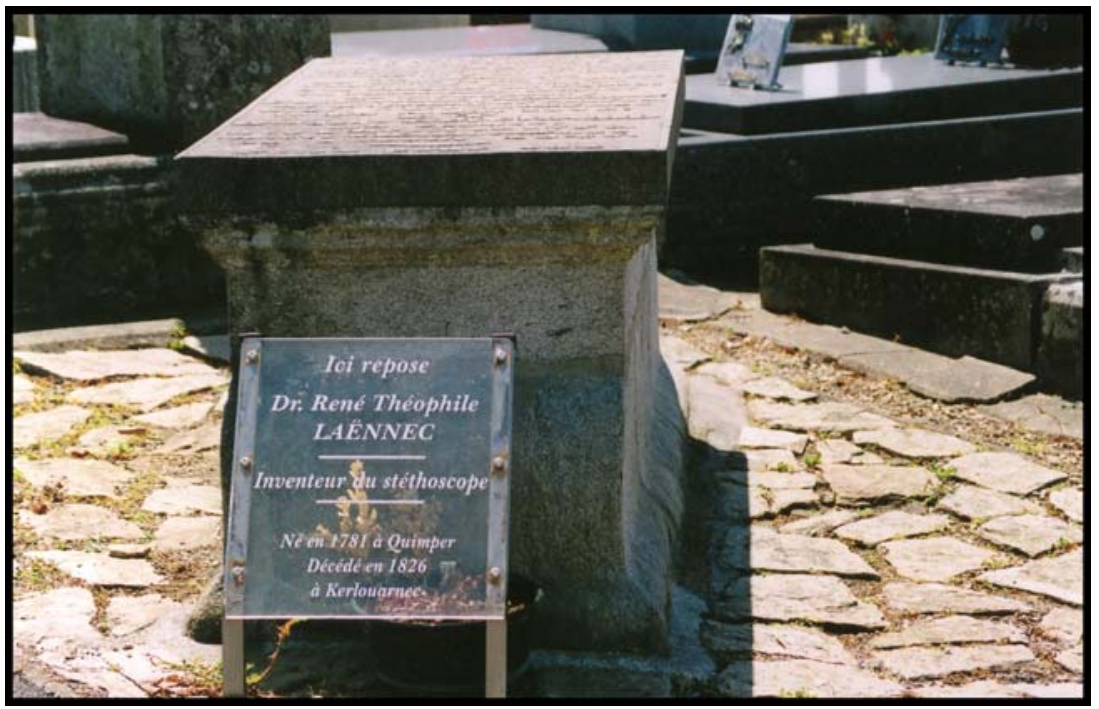

Fig. 6 Laënnec's grave in the cemetery of Ploaré near Douarnenez, not far from Laënnec's estate in Kerlouarnec (Finistère, Brittany)

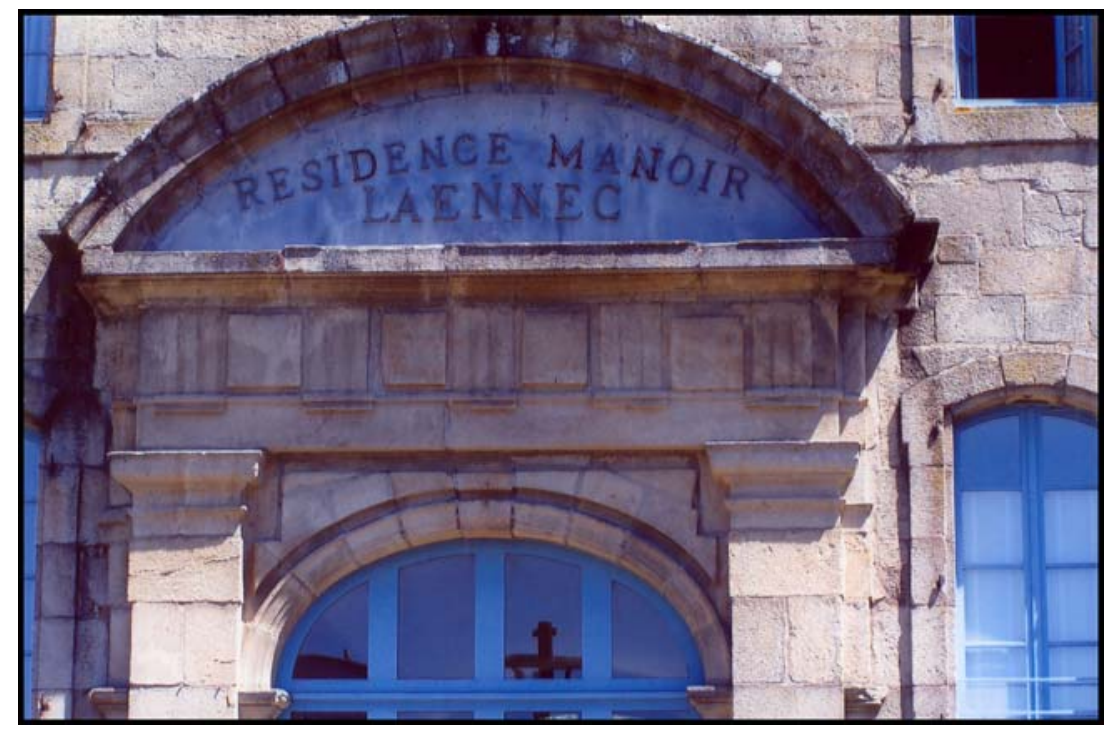

Fig. 7 The old seminary in Quimper, used as hospital, which received the name Laënnec in 1949 (today a retirement home under the name "Residence Manoir Laënnec). The newly built Center Hospitalier of Quimper carries the name Théophile René Laënnec 